\title{
Specimen Level and Component Level Simulations of Fatigue Crack Growth Behavior under Cyclic Bending
}

\author{
R. Suresh Kumar \\ Indira Gandhi Centre for Atomic Research, Homi Bhabha National Institute, Kalpakeam, India - 603 102, India \\ ersureshkr@gmail.com
}

B.N. Rao

Indian Institute of Technology Madras, Chennai, India

bnrao2018@gmail.com

K. Velusamy, S. Jalaldeen

Indira Gandhi Centre for Atomic Research, Kalpakekam

kvelu@igcar.gov.in,jala@igcar.gov.in

\begin{abstract}
This paper describes a benchmark analysis that was performed to demonstrate numerical simulation capability on fatigue crack growth (FCG) behaviour under cyclic bending. Economic design of a piping system against the leak-before-break (LBB) criteria require an accurate estimate of crack growth behaviour. To this end, two representative geometries were selected. The first model was a plate-type geometry with a specimen-type feature, and the other model was a prototype pipe bend geometry with the component feature. The numerically simulated FCG behaviour was found to agree with published data within engineering accuracy for both the specimen-level and the component-level geometries. Details of the FCG simulation, its validation against benchmark data, and plausible reasons the difference observed in the FCG behaviour of the specimen-level and full-scale component-level geometries are presented in this paper. The results of the FCG simulation strengthen the argument for performing component-level FCG simulation for an accurate demonstration of LBB for the power plant piping systems.
\end{abstract}

KEYwORDS. Leak-Before-Break; Fatigue Crack Growth; Stress Intensification Factor.

\section{OPEN ACCESS}

Citation:Suresh Kumar, R., Rao, B., N., Velusamy, K., Jalaldeen, S., Specimen level and component level simulation of fatigue crack growth behavior under cyclic bending, Frattura ed Integrità Strutturale, 49 (2019) 526-535.

Received: 30.11 .2018

Accepted: 28.05.2019

Published: 01.07.2019

Copyright: (C) 2019 This is an open access article under the terms of the CC-BY 4.0, which permits unrestricted use, distribution, and reproduction in any medium, provided the original author and source are credited. 


\section{INTRODUCTION}

$\mathrm{P}$ ipings are critical systems in power plants and chemical industries. In coal-fired and nuclear power plants, these systems are subjected to many cyclic operating conditions during their service. It is known that cyclic loads exceeding specific magnitudes have a strong potential to cause crack initiation and propagation. However, in the case of Sodium-cooled Fast Reactor (SFR), where the piping system is made up of SS 316LN material, it is possible to detect sodium leakage, (i) due to the ductile nature of SS 316LN and (ii) elaborate sodium leak detection provision. These conditions made SFR design more favourable in demonstrating Leak-Before-Break (LBB) criteria [1]. In the case of SFR piping system, these conditions are respected as per the design criteria given in RCC MRx A16 [2]. The highly conservative method detailed in RCC MRx A16 poses challenges in demonstrating the LBB criteria for small-size low-pressure piping system. Conducting full-scale experiments at the required temperature on all the sizes of the piping system is expensive and time-consuming. Hence, there is a strong need for the development of a reliable numerical method for a quick and economical design of power plant components for LBB. This is the focus of the present paper wherein; benchmark analysis has been carried out towards validation of numerical Fatigue Crack Growth (FCG) simulation. It may be highlighted that the characteristics of FCG had been investigated by many researchers in the past [3-11]. In the present research, two representative geometries studied in the open literature [4-5] have been selected. The selected geometries are (i) a typical plate-type geometry with a specimen-type feature and (ii) a prototype pipe bend with the component feature. As already mentioned that an SFR piping system is subjected to cyclic bending stress variation during its service conditions [1]. The bending stress variation in the SFR piping system has a positive load ratio $(R)$, which is defined as the ratio of the minimum stress $\left(\sigma_{\min }\right)$ to maximum stress $\left(\sigma_{\max }\right)$ during the cyclic load. Towards comparing the FCG behaviour of the specimen level plate-type geometry, data reported in [4] is used, and for the prototype geometric simulation, the full-scale pipe bend test data reported in [5] is used.

\section{BENCHMARK DATA}

\section{Plate specimen data}

hapuliot et al. [4] have investigated FCG behaviour in a plate specimen, by detailed experimentation. The geometric and loading details are given in Fig.1. The dimensions of the test specimen are $350 \mathrm{~mm}$ wide, $250 \mathrm{~mm}$ height and $20 \mathrm{~mm}$ thickness. An elliptical initial surface crack is provided at the centre of the plate as depicted in Fig.1.

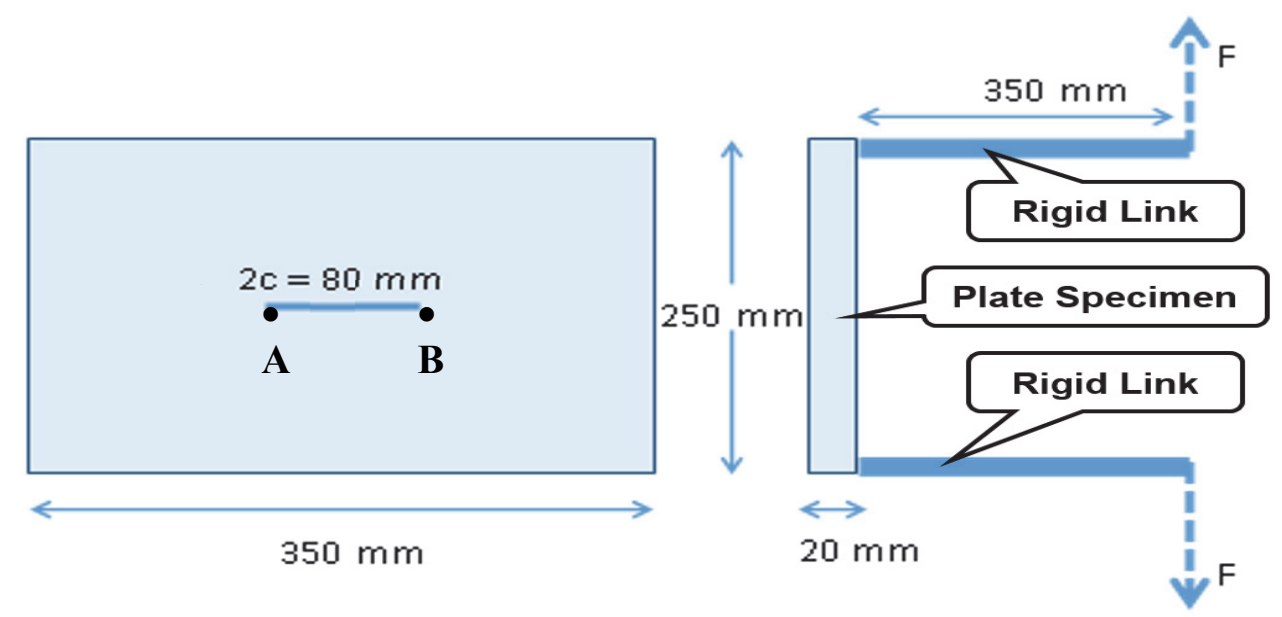

Figure 1: Geometric and loading of the plate specimen [4]

The plate specimen is made up of SS 316 LN material. The essential data required for modelling the FCG behaviour of this geometry are presented in Tab. 1. 


\begin{tabular}{|c|c|c|c|c|}
\hline $\mathrm{E}(\mathrm{MPa})$ & $\begin{array}{l}\text { Maximum Load } \\
F_{\max }(\mathrm{kN})\end{array}$ & $\begin{array}{l}\text { Minimum Load } \\
\mathrm{F}_{\min }(\mathrm{kN})\end{array}$ & $\mathrm{a}_{0}(\mathrm{~mm})$ & $2 \mathrm{C}_{0}(\mathrm{~mm})$ \\
\hline 195500 & 22.5 & 3.1 & 2.0 & 80.0 \\
\hline
\end{tabular}

Table 1: Essential data used for modelling FCG in a plate specimen [4].

The plate has been subjected to cyclic load variation with a maximum load of $22.5 \mathrm{kN}$ and a minimum load of $3.1 \mathrm{kN}$, with a load ratio of 0.138 . The measured crack length as a function of the number of cycles is presented in Fig.2. These data are used for assessing the validity of computational prediction of FCG behaviour in plate specimen.

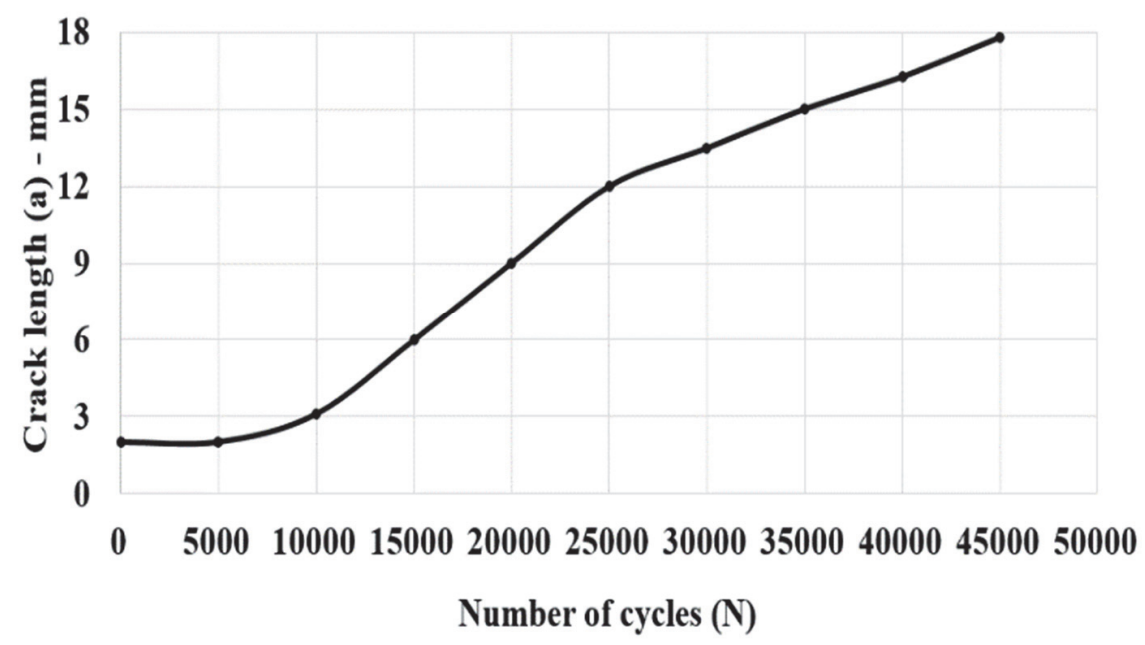

Figure 2: Benchmark data for the plate specimen [4]

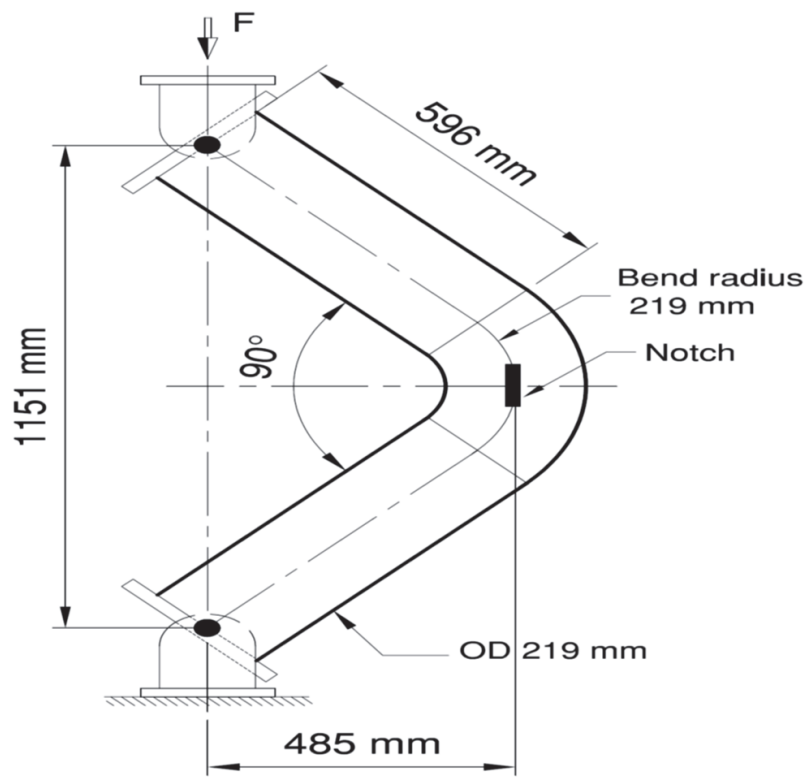

Figure 3: Geometrical and loading details of the pipe bend 


\section{Pipe bend data}

The data from literature includes the experimental study on FCG behaviour of a full-scale pipe bend of $219 \mathrm{~mm}$ outer diameter and thickness of $15.12 \mathrm{~mm}$ [5], made of carbon steel (SA333 Gr.6 grade) material. The schematic of the test pipe specimen is shown in Fig. 3. The cyclic test was carried out with a load ratio of 0.1, and other relevant data considered in the computational modelling of the FCG behaviour are presented in Tab. 2. The measured crack length as a function of the number of cycles is depicted in Fig. 4.

\begin{tabular}{ccccc}
\hline Material & $\begin{array}{c}\text { Maximum Load } \\
\mathrm{F}_{\max }(\mathrm{kN})\end{array}$ & $\begin{array}{c}\text { Minimum Load } \\
\mathrm{F}_{\min }(\mathrm{kN})\end{array}$ & $\mathrm{a}_{0}(\mathrm{~mm})$ & $2 \mathrm{C}_{0}(\mathrm{~mm})$ \\
SA350LF2 & -150 & -15 & 2.0 & 87.0 \\
\hline
\end{tabular}

Table 2: Data used in modelling FCG in a pipe bend [5-6].

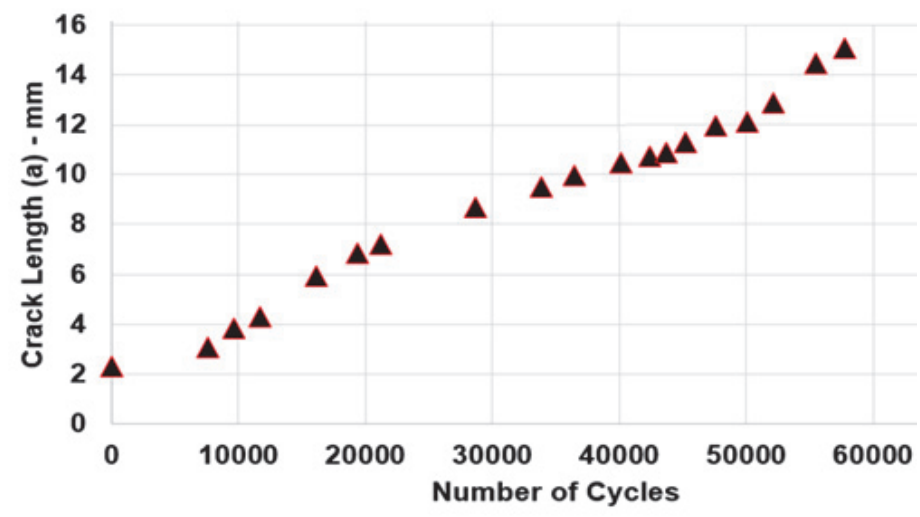

Figure 4: Benchmark data for pipe bend geometry [5]

\section{STATIC ANALYSIS}

$\mathrm{t}$ the outset, static analysis has been carried out for both the plate as well as the pipe bend geometries, to check the
correctness of the numerical model. These results are presented below:

\section{Plate specimen}

The plate geometry has been modelled using 3-Dimensional solid element along with the associated rigid loading connections for the application of the required bending moment. As already indicated that the maximum load of $22.5 \mathrm{kN}$ is applied [4]. The mode-1 stress distribution under the application of the external load is shown in Fig.5. It is clear that the inner surface of the plate is under the maximum tensile stress $(319 \mathrm{MPa})$, while the outer surface is under the maximum compressive stress $(-290 \mathrm{MPa})$. Thus, for the FCG simulation, the crack is provided at the inner surface of the plate in the horizontal direction, as shown in Fig. 1.

\section{Pipe bend geometry}

The $219 \mathrm{~mm}$ outer diameter, $15.1 \mathrm{~mm}$ thick pipe bend with a radius of $219 \mathrm{~mm}$ is also modelled using 3-D solid element. The pipe bend is subjected to the maximum load of $150 \mathrm{kN} \mathrm{[5].} \mathrm{Application} \mathrm{of} \mathrm{this} \mathrm{force} \mathrm{in} \mathrm{the} \mathrm{direction} \mathrm{as} \mathrm{indicated} \mathrm{in}$ Fig.6 with a moment arm of $485 \mathrm{~mm}$, creates an in-plane bending moment in the pipe bend, which leads to a closing of the pipe bend, and thereby the pipe cross-section becomes oval. At this condition, the stress distribution responsible for the mode-I crack propagation is presented in Fig.6. It is clear that the preferred location and the orientation to insert the initial defect on the pipe bend is at the crown location along the longitudinal direction. 


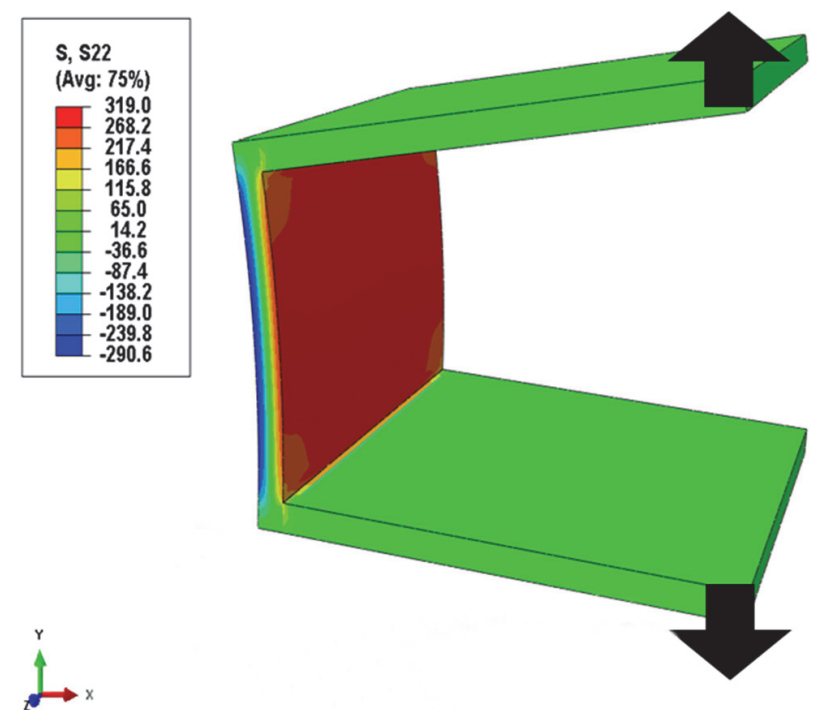

Figure 5: Mode-I crack initiation stress $(\mathrm{MPa})$ distribution in the plate specimen

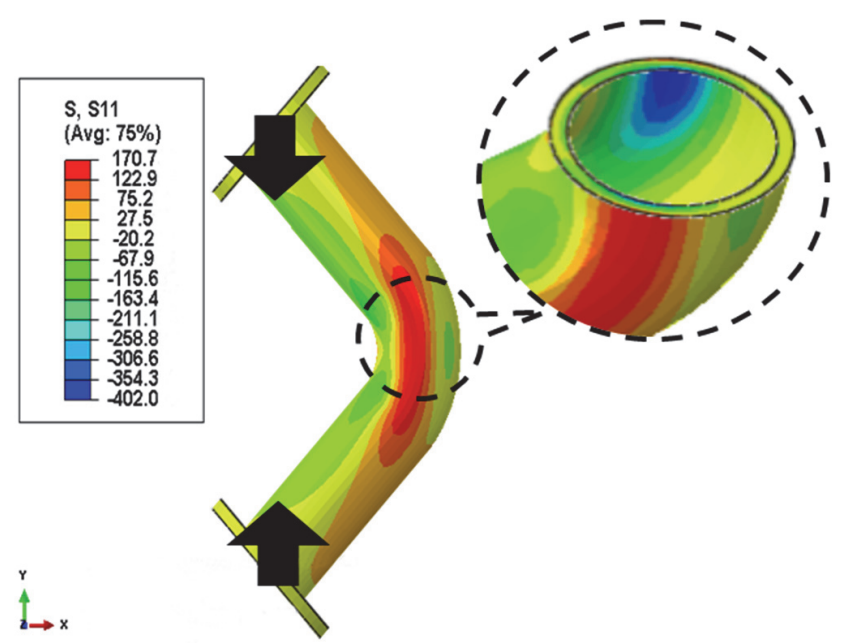

Figure 6: Mode-I crack initiation stress (MPa) distribution in the pipe bend specimen

\section{FATIGUE CRACK GROWTH (FCG) SIMULATION}

he FCG simulation for both the plate, as well as pipe bend specimen, has been performed using the FRANC3D software. This software is adopted as it can simulate 3-D FCG analysis together with the general-purpose Finite

Element (FE) solvers. The magnitude and direction of the crack growth depend upon the stress intensity factor (SIF) and the local 'Kink angle' respectively. Kink angle is defined as the angle that maximises the ratio between maximum SIF ( $\mathrm{K}_{\mathrm{I}}{ }^{\max }$ ) computed based on the maximum tensile stress at the crack front and the directionality dependent material resistance to crack growth $\left(\mathrm{K}_{\mathrm{c}}{ }^{\theta}\right)$. The convergence of the crack growth simulation is decided by maximising the ratio $\mathrm{K}_{\mathrm{I}}{ }^{\max } / \mathrm{K}_{\mathrm{c}}{ }^{\theta}$. The direction of crack propagation is determined based on the 'Kink angle' measurement at the base of the crack front. The SIF is computed based on the M-integral concept at mid-side nodes along the crack front using the maximum tensile stress [12]. The sub modelling concept, deployed in the FRANC3D, helps in local mesh-refinement at the cracked portion of the component geometry for efficient computation. Higher mesh density is provided for a shallow crack. Also, a pattern of elements with controlled mesh size and shapes are placed around the crack front for accurate estimation of SIF. 
These elements take the form of generalised cylindrical tubes with the crack fronts serving as the axes. 3-D Wedge shaped elements are placed immediately adjacent to the crack fronts, and rings of brick elements surround the crack front.

The magnitude of SIF depends upon the crack dimensions, applied stress and other geometrical parameters. The local direction of crack advancement is determined based on the local 'kink' angle.

The FCG simulation is performed as per the Paris law, defined as $\mathrm{da} / \mathrm{dN}=\mathrm{C}(\Delta \mathrm{K})^{\mathrm{m}}$, where $d a / d \mathrm{~N}$ is in $\mathrm{m} / \mathrm{cycle}, \Delta K$ is in $\mathrm{MPa} \sqrt{\mathrm{m}}$ and $C \& m$ are the respective FCG material parameters. The values of $C$ and $m$ used for the plate geometry are 1.2 x $10^{-8}$ and 2.84, respectively [4]. The corresponding values for the plate geometry are $3.982 \times 10^{-12}$ and 3.188 , respectively [5]. The results of the FCG analysis are presented below.

\section{FCG on Plate Specimen}

For the plate specimen, the initial elliptical surface crack length $\left(2 \mathrm{c}_{0}\right)$ is $80 \mathrm{~mm}$, and the crack depth (a $\left.a_{0}\right)$ is $2 \mathrm{~mm}$. The locations A and B in Fig.7 represent the crack surface location (crack length 'c' direction) and the deepest crack location (crack depth 'a' direction). The orientation of the initial crack is along the X-direction (ref. Fig. 7) such that the applied bending stress will enhance the mode- 1 crack propagation. The finite element model of the cracked geometry is shown in Fig.7. There are 245964 elements in the specimen. It houses a combination of the 3D tetrahedron, hexahedron and wedge elements.

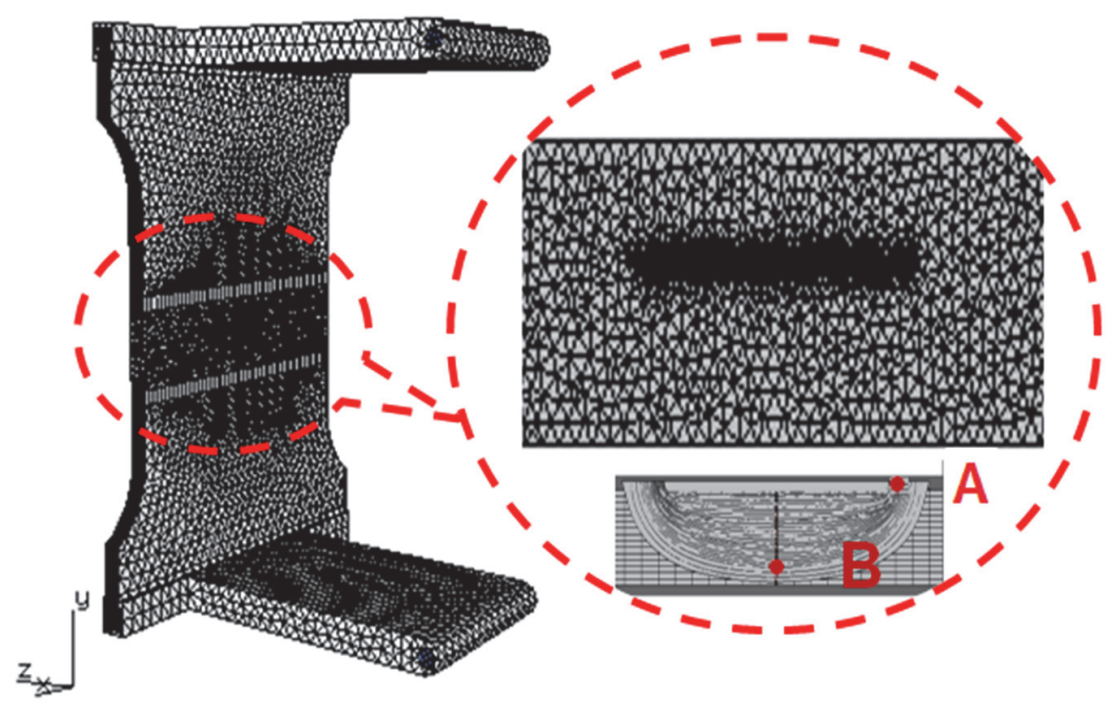

Figure 7: FE sub-model of the cracked plate geometry

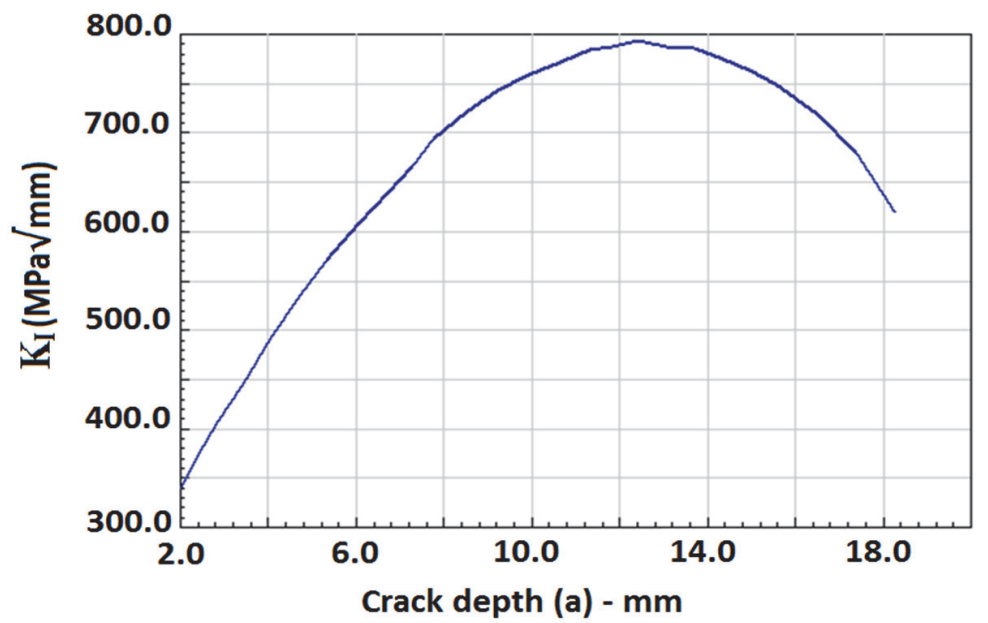

Figure 8: SIF variation for plate geometry at the critical location - B 
As already indicated, the crack growth rate depends upon the SIF at the crack front. The numerically obtained $\mathrm{K}_{\mathrm{I}}$ along the crack front indicates that $\mathrm{K}_{\mathrm{I}}{ }^{\mathrm{B}}$ (SIF at location B in Fig.7) is higher than $\mathrm{K}_{\mathrm{I}}{ }^{\mathrm{A}}$ (SIF at location A in Fig.7). This is due to the high crack size aspect ratio (c/a). Subsequently, the critical location SIF $\left(\mathrm{K}_{\mathrm{I}} \mathrm{B}\right)$ variation during the advancement of the crack is presented in Fig.8. It shows that $\mathrm{K}_{\mathrm{I}}$ increases with an increase in 'a/ $\mathrm{t}$ ' ratio up to 0.6 , and then it decreases, which is attributed to the influence of neighbouring compressive stress zone, as shown in Fig.5.

The predicted FCG behaviour of the plate specimen is compared with the experimental data [4] in Fig.9. It shows that the numerically estimated crack growth is in good agreement with the experimental results.

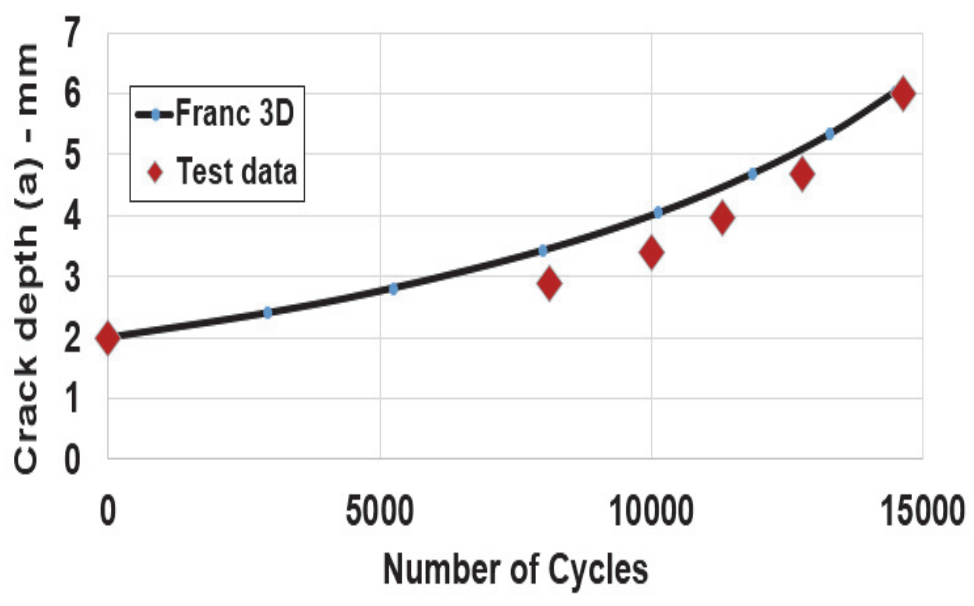

Figure 9: Comparison of 'a' Vs 'N' for a plate specimen

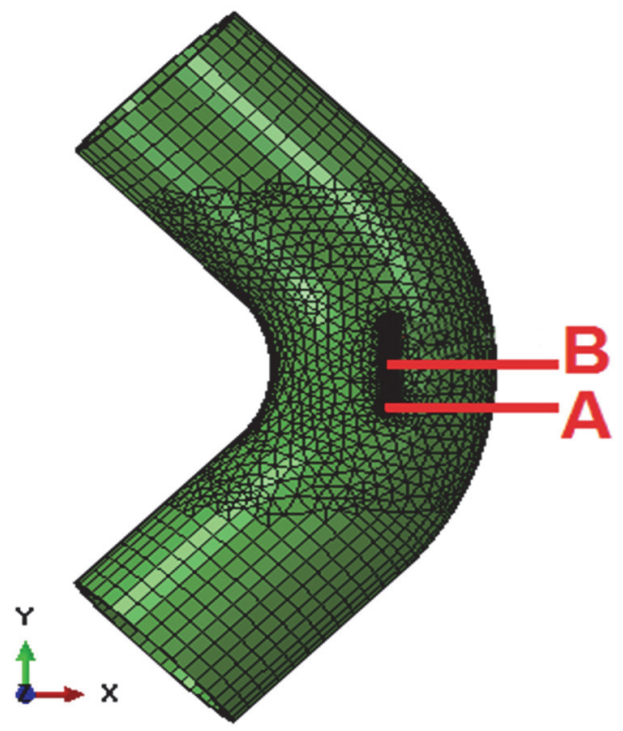

Figure 10: FE sub-model of the cracked pipe bend geometry

\section{FCG on Pipe Bend}

The FCG analysis for the pipe bend geometry is carried out with an initial elliptical surface crack length $\left(2 \mathrm{c}_{0}\right)$ of $87 \mathrm{~mm}$ and depth ( $\left.\mathrm{a}_{0}\right)$ of $2 \mathrm{~mm}$. The locations A and B in Fig.10 represent the crack surface location (crack length 'c' direction) and the crack deepest location (crack depth 'a' direction). Cyclic bending stress is applied with a load ratio of 0.1. The large shallow surface crack is introduced in the hoop tensile stress region (outer surface at the crown location from Fig. 6) of the pipe bend. Simulation of a crack along the axial direction on the outer surface, as shown in Fig.3, will enhance the mode-1 crack propagation. The sub-model concept is adopted in this case and the respective FE mesh given in Fig.10. The difference between the full model and the sub-model will be clear with the comparison of Figs. 6 and 10, respectively. The sub model contains a combination of the 3D tetrahedron, hexahedron and wedge elements. In total, there are 167969 elements against 
245964 in the case of plate geometry. The total number of elements can also be further reduced by adjusting the boundary of the sub model without affecting the results.

The SIF variation extracted from FRANC3D at the critical location (B from Fig.10) during FCG is shown in Fig.11. It indicates that $K_{I}$ increases with an increase in ' $a$ ' up to ' $a / t$ ' ratio of $0.4(a=6 \mathrm{~mm})$ and then it decreases, due to the influence of the neighbourhood compressive stress zone as evident from Fig.6.

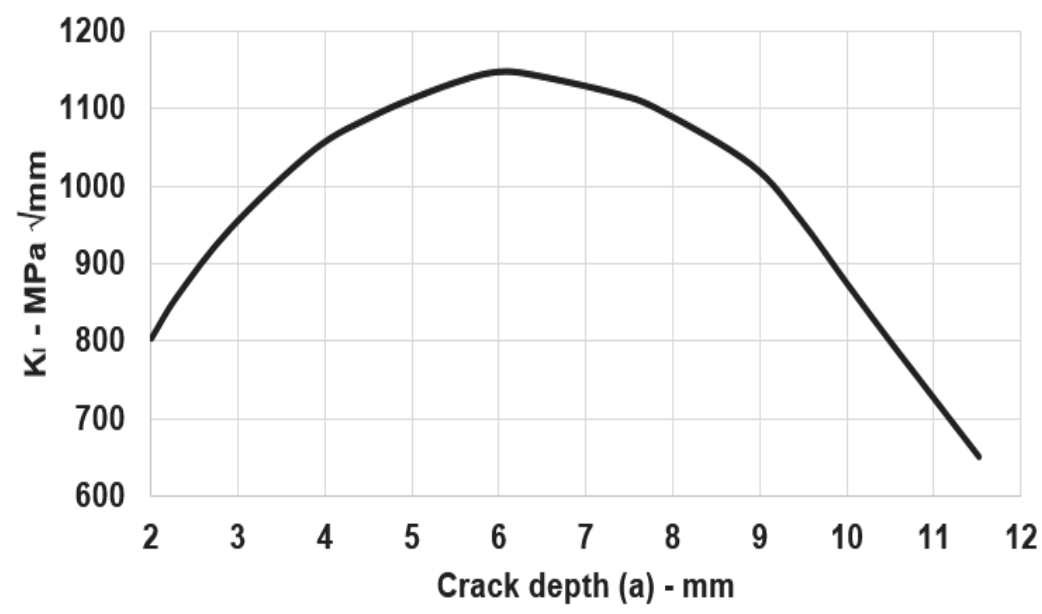

Figure 11: SIF variation for the pipe bend at the critical location-B

The numerically predicted estimate of FCG behaviour of the pipe bend is compared with the experimental data and depicted in Fig.12. It is clear that the numerically predicted crack growth is in good agreement with the experimental results. The reduction in the rate of crack growth beyond $6 \mathrm{~mm}$ is due to the influence of low $\mathrm{K}_{\mathrm{I}}$ value.

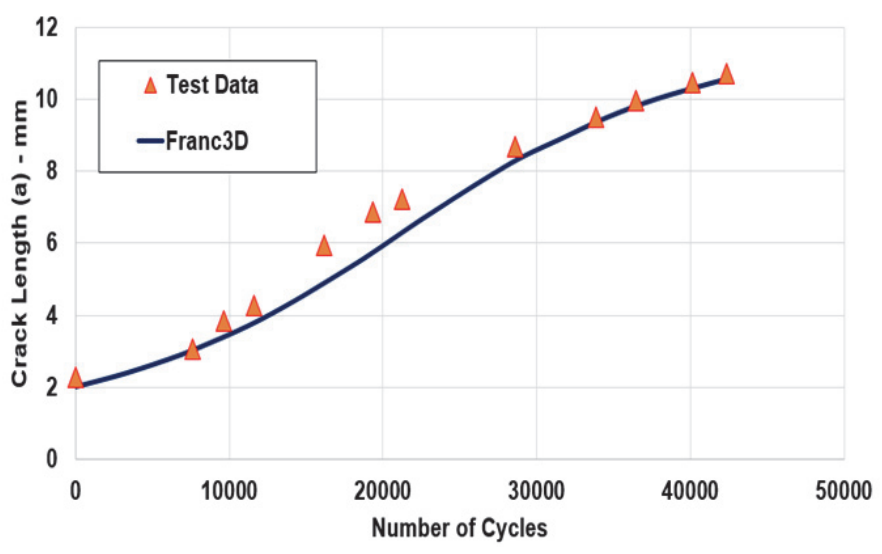

Figure 12: Comparison of 'a' Vs 'N' on pipe bend

\section{SUMMARY AND CONCLUSIONS}

wo representative geometries have been selected from the literature towards validating numerical simulation of FCG behaviour. The selected geometries are a plate specimen and a representative full-scale pipe bend. The important observations are summarised below.

SIF is computed at the mid-side nodes along the crack front based on M-integral concept. The deployment of submodelling concept has made the computation of FCG behaviour more effective. The crack growth direction is decided by maximising the 'Kink angle' measurement at the base of the crack front using the maximum tensile stress. This also enhances the accuracy of the numerical model. 
- The numerical crack growth estimates at both specimen level as well as the component level, have been validated with better engineering accuracy with the available experimental data.

- The SIF is seen to exhibit a non-monotonic variation to the crack depth ratio, attaining a peak value at a critical ' $a / t$ ' ratio. The estimated results show that the variation of $K_{I}$ for the pipe geometry decreases earlier than that of the plate geometry. This early reduction is due to the influence of the global compressive stress present at the leading edge of the crack propagation.

- $\quad$ Fatigue crack growth rate is found to be lower for the pipe geometry than that of the plate geometry under cyclic bending condition. This is due to the presence of the higher amount of asymmetric bending stress variation in the case of the pipe bend geometry than that of the plate geometry under the application of bending moment.

- $\quad$ The difference in material property may also influence the FCG behaviour. This can be confirmed by simulating FCG for both the plate and pipe bend geometries with identical material properties, load ratio and cyclic stress variation.

In the case of the SFR piping system, the leading cause of fatigue load for crack propagation is the cyclic bending stress. The above results indicate that a prototype level simulation is essential for an accurate estimation of parameters used in the LBB demonstration.

\section{ACKNOWLEDGEMENTS}

uthors acknowledge the support rendered by Shri. Santhosh N L \& Shri. Kaushik, DHIO Research and
Engineering, Bangalore for their service related to FRANC3D software.

\section{REFERENCES}

[1] Suresh Kumar, R., Jalaldeen, S., Selvaraj, P., Chellapandi, P.(2011). High Temperature Design of Class-1 Piping Systems in Sodium Cooled Fast Breeder Reactor. Transactions, SMiRT 21, 6-11 November, 2011, New Delhi, India, p. Div-VI: Paper ID\# 792.

[2] Afcen. (2012). Section III - Tome 1 - Subsection Z - Appendix A16: Guide for prevention of fast fracture , Leak Before Break analysis and defect assessment, RCC MRx.

[3] Chellapandi, P., Srinivasan, R., Biswas, A., Chetal, S.C., Bhoje, S.B. (2003).Leak Before Break Investigation on Sodium Piping for Prototype Fast Breeder Reactor. Transactions of the 17th International Conference on Structural Mechanics in Reactor Technology (SMiRT 17) Prague, Czech Republic, p. 3216.

[4] Chapuliot, S., Chaudat, T., Mineau, V., Moulin, D. (1996). Fatigue growth of semi-elliptical cracks in plates subjected to bending, ASME PVP, Fatigue \& Fracture, 323, pp 291-298.

[5] Arora, P., Singh, P.K., Bhasin, V., Vaze, K.K., Pukazhendhi, D.M., Gandhi, P., Raghava, G. (2013). Fatigue crack growth behavior in pipes and elbows of carbon steel and stainless steel materials, Procedia Eng., 55, pp. 703-709. DOI: $10.1016 /$ j.proeng.2013.03.318.

[6] Singh, P.K., Bhasin, V., Vaze, K.K., Ghosh, A.K., Kushwaha, H.S., Murthy, D.S.R., Gandhi, P., Sivaprasad, S. (2008). Fatigue studies on carbon steel piping materials and components: Indian PHWRs, Nucl. Eng. Des., 238(4), pp. 801813, DOI: 10.1016/j.nucengdes.2007.09.002.

[7] Chattopadhyay J., B. Dutta, and H.Kushwaha. (1999). Leak-before-break qualification of primary heat transport piping of 500 MWe Tarapur Atomic Power Plant, Int. J. Press. Vessel. Pip., 76(4), pp. 221-243,

DOI: 10.1016/j.nucengdes.2016.02.013.

[8] Sethuraman, R., C. L. Rao, and P.Kameswara R. (1999). Fatigue crack growth of semielliptical surface cracks in curved geometries, J. Structuctral Eng., 26(1), pp. 81-86, DOI: 10.1177/0021998305055549.

[9] Riddell, W.T., Ingraffea, A.R., Wawrzynek, P.A. (1997). Experimental observations and numerical predictions of threedimensional fatigue crack propagation, Eng. Fract. Mech., 58(4), pp. 293-310, DOI: 10.1016/S0013-7944(97)00122-7.

[10] Rao, C.L., Sethuraman, R., Bhoje, V., Chellapandi, P. (2000). Fatigue Crack Propagation Studies on a Semi-Elliptical Surface Crack in a Plate Subjected to Bending Loads, ASMEPVP, 404, pp. 37-44.

[11] Nagapadmaja, P., Kalyanaraman, V., Kumar, S.R.S., Chellapandi, P. (2008). Experimental study on LBB behaviour of 
LMFBR pipe elbows, Int. J. Fatigue, 30(3), pp. 574-84.

[12] Liang, R.Z., Rui, Z.C., Liang, Z.Y., Bo, Z.H., Zuo, J., Engineering, D.U., Zhou, X. (2010).M-integral for Stress Intensity Factor Based on XFEM. Proceedings of the Third International Symposium on Electronic Commerce and Security Workshops(ISECS '10), pp. 226-30. 